\title{
'They're more like ordinary stroppy British women': attitudes and expectations of maternity care professionals to UK-born ethnic minority women
}

\author{
Shuby Puthussery, Katherine Twamley, Seeromanie Harding1, Judith Mirsky, \\ Maurina Baron, Alison Macfarlane \\ Department of Midwifery, City University, London; ${ }^{1}$ MRC Social and Public Health Sciences Unit, University of Glasgow, Glasgow, UK
}

\begin{abstract}
Objective: To explore the attitudes and expectations of maternity care professionals to UK-born ethnic minority mothers.

Methods: Qualitative in-depth interviews with 30 professionals from eight NHS maternity units in England that provide services for large proportions of women of black Caribbean, black African, Indian, Pakistani and Irish descent.

Results: All the professionals reported providing care to both UK-born and migrant mothers from ethnic minorities. Most of them felt that they could differentiate between UK-born and migrant mothers based mainly on language fluency and accent. 'Westernized dress' and 'freedom' were also cited as indicators. Overall, professionals found it easier to provide services to UK-born mothers and felt that their needs were more like those of white English mothers than those of migrant mothers. UK-born mothers were generally thought to be assertive and expressive, and in control of care-related decision-making whereas some South Asian Muslim women were thought to be constrained by family influences. Preconceived ideas about ethnic minority mothers' tolerance of pain in labour, use of pharmacological pain relief measures and mode of delivery were recurring themes. Women's education and social class were felt to be major influences on the uptake of maternity care, regardless of ethnicity.

Conclusions: Professionals appeared to equate the needs of UK-born ethnic minority women with those of white English women. Overall, this has positive implications for care provision. Despite this, specific behavioural expectations and unconscious stereotypical views were evident and have the potential to affect clinical practice.
\end{abstract}

\section{Introduction}

The behaviour of health care professionals has the potential to contribute to ethnic disparities in access to services and in managing care. However, research focusing specifically on the attitudes and expectations held by professionals about ethnic minorities is limited. The Race Relations (Amendment) Act (2000) and National Health Service (NHS) policies require health services to promote equality and be responsive to cultural diversity. ${ }^{1}$ Such services are urged to take a woman-focused approach to care that is accessible and responsive to local needs. ${ }^{2}$ Policies about the care of ethnic minority

Shuby Puthussery PhD, Research Officer, Katherine Twamley MSc, Research Officer, Judith Mirsky MSc, Research Officer, Maurina Baron MBA, Lecturer, Alison Macfarlane FFPH, Professor of Perinatal Health, Department of Midwifery, City University, 20 Bartholomew Close, London EC1A 7QN, UK; Seeromanie Harding MSc, Head of Programme, Ethnicity and Health, MRC Social and Public Health Sciences Unit, University of Glasgow, Glasgow, UK.

Correspondence to: A.J.Macfarlane@city.ac.uk mothers are built on research that has focused on the needs of migrant women, ${ }^{3}$ the relevance of which to UK-born ethnic minority mothers is questionable.

This article explores maternity care professionals' attitudes to mothers of Indian, Pakistani, black African, black Caribbean and Irish descent born in the UK.

\section{Professional attitudes and care provision}

There is extensive evidence, mainly from the United States, to suggest that access to services and quality of care are influenced not only by the technical skills and knowledge of practitioners but also by their attitudes towards their patients. ${ }^{4-8}$ Professionals' understandings of population-based data may function as stereotypes, and can be applied to assessments and perceptions of individuals, regardless of individual differences. ${ }^{4}$ Most of this research has described disparities in treatment for coronary artery disease, but disparities have also been documented in access to pain control and care 
for children and at-risk young people. Research in both the US and the UK has shown differences in mental health services. The research in the US produced evidence that sociodemographic characteristics of patients have an impact on both the behaviour of doctors during medical encounters ${ }^{9}$ and on the diagnoses and treatments received. ${ }^{4-6}$ If group characteristics influence professionals' perceptions about their clients, this may affect both clinical decision-making and client satisfaction and compliance, contributing to disparities in access to services.

The relatively small amount of research related to maternity care in the UK has focused on immigrant ethnic minority women. This has demonstrated their vulnerability to stereotyping. ${ }^{8,10,11}$ A study from east London about midwives' stereotypes of South Asian women reflected themes like difficulty of communicating with the women, women's lack of compliance with care and misuse of services, their tendency to make a fuss about nothing and lack of normal maternal instinct. ${ }^{8}$

\section{Difficulties in communication}

Studies on ethnic minority women's maternity experiences highlight difficulties faced by non-English-speaking women. ${ }^{10,12-14}$ Some authors argue that policies and midwifery practice assume the population is white and English-speaking. ${ }^{3,8,10,14}$ For instance, a study of Somali refugees in west London reported unequal access to maternity services due to inadequate provision of interpreting services, stereotyping and racism from staff, with a lack of understanding of cultural differences. ${ }^{14}$

Poor communication, even without major language problems, has been shown to affect the experiences of women from ethnic minority groups. A study of the birth experiences of UK-born South Asian Muslim women highlighted the poor quality of communication between midwives and the women in their care. ${ }^{11}$ Problems of communication are exacerbated by interpersonal issues like staff stereotypes, racism and cultural barriers with providers. $8,12-16$

Based on this evidence, this paper explores professionals' perceptions about UK-born ethnic minority mothers on aspects such as ethnic background, social status and class, and discusses the implications for service delivery.

\section{Methods}

Health professionals directly involved in providing maternity and postnatal care were recruited from eight maternity units in London and Birmingham catering for a significant proportion of mothers from black Caribbean, black African, Indian, Pakistani and Irish backgrounds. The professionals were identified using combinations of purposive and convenience sampling procedures and the use of key informants. Respondents were midwives, obstetricians, general practitioners, health visitors and practice nurses with different ethnic backgrounds, gender and years of experience
(Table 1). The final number of interviews was based on 'redundancy', when no new information appeared to be forthcoming. ${ }^{17}$

At the initial contact, all the professionals were given information about the study, the length of the interview and the scope of questions. Consent to participate in the study was also sought. The interviews were in-depth and semi-structured using a topic guide. Interviews were audio-taped with the permission of the participants. Respondents were first asked about their experiences of delivering care to mothers from particular ethnic groups and then prompted about care provision to UK-born mothers in comparison with both migrant and white indigenous mothers. The interviews were conducted by two of the research team. The average duration was 45 minutes. Most were conducted in the office of the interviewee or in a convenient room which was free from interruptions and where privacy was ensured. All the interviews were transcribed. The texts were then coded and organized using NVivo. ${ }^{18}$ Analysis was based on grounded theory. ${ }^{19}$ Initial codes were grouped into more abstract levels of codes or themes. The study was approved by the South East Multicentre Research Ethics Committee and each NHS Trust's Research and Development Committee.

\section{Results}

\section{Distinguishing between migrant and UK-born mothers}

All the respondents reported providing care to both migrant and UK-born minority women. Except for those providing care to Irish populations, the majority were able to distinguish them, mainly by language fluency, accent or general ability to articulate:

\footnotetext{
'Yes. I think so. Generally people who are first, who are born in this country but are Indian will speak with a London accent and will speak fluently, and people who aren't born in this country generally will speak with an Indian accent ... so they will always speak English, with a bit of a London accent, which is very distinguishable. So I think you can always distinguish, yes.' (Obstetrician, female, Irish)
}

The 'Westernized dress' and 'freedom' of UK-born women were also cited as distinguishing features. Dress was perceived to be an important sign, not only of generational status but also of the autonomy or freedom of Muslim women. Women who wore a veil or less Western clothing were assumed to be from a traditional stricter family:

'You can tell by the way they dress as well, a lot of the time. You see a lot of second-generation Muslims now wearing more Westernized clothes, and not covering up completely. And you tend to know by looking that they've got a little bit more freedom and probably will use the services offered more. Whereas if you go into a home and they're still in their own dress you tend to know that they're a little bit more ... in a little bit more stricter of a family.' (Breastfeeding counsellor, female, Irish)

Respondents felt that it was generally difficult to distinguish between UK-born Irish and the general white 
Table 1 Profile of the health care professionals

\begin{tabular}{|c|c|c|c|c|}
\hline ID code & Gender & Ethnic background & Predominant ethnic group using the service & Experience (years) \\
\hline Midwife 1 & Female & Black Caribbean & \multirow[t]{8}{*}{ Black African and black Caribbean } & 17 \\
\hline Midwife 2 & Female & White British & & 2.5 \\
\hline Obstetrician 1 & Female & White British & & 12.5 \\
\hline Obstetrician 2 & Male & White British & & 6 \\
\hline Neonatologist 1 & Male & Asian & & 10 \\
\hline Midwife 3 & Female & White British & & 9 \\
\hline Midwife 4 & Female & White British & & 18 \\
\hline Midwife 5 & Female & Black Caribbean & & 25 \\
\hline Midwife 6 & Female & Irish & \multirow[t]{3}{*}{ Indian } & 15 \\
\hline Midwife 7 & Female & White British & & 16 \\
\hline Practice Nurse 1 & Female & Asian British & & 3 \\
\hline Midwife 8 & Female & Irish & \multirow[t]{3}{*}{ Indian, black Caribbean, Pakistani } & 16 \\
\hline General Practitioner 1 & Male & Indian & & 24 \\
\hline Health visitor 1 & Female & Black Caribbean & & 20 \\
\hline Midwife 9 & Female & White British & \multirow[t]{4}{*}{ Irish } & 5 \\
\hline Midwife 10 & Female & White British & & 10 \\
\hline Midwife 11 & Female & Irish & & 4 \\
\hline Obstetrician 4 & Male & Irish & & 1.2 \\
\hline Obstetrician 5 & Female & Irish & Indian & $<1.0$ \\
\hline General Practitioner 2 & Female & Asian & Indian, Pakistani, Bangladeshi & Not known \\
\hline Midwife 12 & Female & Black Caribbean & \multirow[t]{3}{*}{ Black African and black Caribbean } & Not known \\
\hline Midwife 13 & Female & Mixed & & 14 \\
\hline Breastfeeding Counselor 1 & Female & Irish & & 33 \\
\hline Midwife 14 & Female & Not known & \multirow[t]{2}{*}{ Indian, Pakistani, Bangladeshi } & Not known \\
\hline Link Worker 1 & Female & Bengali & & Not known \\
\hline Midwife 15 & Female & Not known & \multirow[t]{3}{*}{ Black African and black Caribbean } & Not known \\
\hline Midwife 16 & Female & White British & & 21 \\
\hline Breastfeeding Counselor 2 & Female & Black Caribbean & & 15 \\
\hline
\end{tabular}

population. The 'invisibility' of second-generation Irish mothers may have contributed to a repeated emphasis that they did not consider Irish second-generation women as a group with particular maternity needs.

\section{Easier to provide services}

Many of the professionals found it easier to provide services to UK-born than to migrant mothers. The language proficiency of the former was perceived by most professionals as a key advantage over migrant women:

'I think you can converse, certainly because there is no language problem, you can converse better with those who are second-generation women. So you don't have the language problem... It's much easier if they've been born in the country and brought up here, but if they're new to the country and we can't communicate with them, language is a big problem.' (Midwife, female, white British)

The UK-born mothers were also perceived to have a better understanding of how the system works than migrant mothers. The language competence and their familiarity with the system led many professionals to think that generally, the needs of UK-born mothers were more like those of 'ordinary stroppy British women' than to those of migrant mothers. As expressed by one of the midwives from a maternity unit used by a significant proportion of black Caribbean and African women, UK-born women 'seem to be pretty good and seem to know what they can get and where to get it and what the expectations are'. (Midwife, female, white British)

A theme that repeatedly came up was the perceived impact of education and social class on use of services. This was most obvious in the accounts of the professionals in units with a large proportion of Irish women. Social class coupled with education influenced 'compliance' with care during pregnancy. Middle class UK-born women were thought to begin antenatal care early. Mothers who delayed care were felt generally to be socially disadvantaged:

'The mums that you worry about that don't come for antenatal care are sometimes mums that have got other risks that you worry about, and those other risks are possibly domestic violence, social exclusion, sometimes learning difficulties, mental health problems, drugs or substance abuse. Or other child protection issues.' (Midwife, female, white British)

Professionals also associated a woman's level of education with her attendance at antenatal classes and knowledge of maternity issues:

'I think that's linked to education, I don't think it's necessarily linked to anything else.' (Midwife, female, Irish) 
'Again it depends on their education. Some of them will access, will want to access, antenatal classes and come to them.. Others will be very reluctant... So I think it does come down to what their education is.' (Midwife, female, white British)

\section{Assertive and expressive}

The predominant impression was that UK-born women are not as submissive as migrant women and were more empowered and autonomous in decision-making. Professionals also found them much more questioning and 'not shrinking violets'. This view came up consistently in the interviews with professionals providing services to mothers with black African and Caribbean backgrounds:

'The second-generation black Caribbean will question, definitely. They're not that ... they wouldn't be so accepting. They would want to know more, they would question ... yeah, they would challenge us more.' (Midwife, female, Irish)

Professionals distinguished between two types of UK-born South Asian Muslim women: those 'under the thumb' and those 'breaking away'. As expressed by one midwife, those who live at home tend to stay within the influence of the family and be more traditional and conservative, identify more with the minority community and have less freedom in decision-making:

'There are two different kinds of second generation... You've got the ones still pampered, still in the house, the young ones, and then you've got the ones who've gone further, and are educated, like they've gone to college, they've gone to uni, got a job and moved out. And they're the ones who are breaking away... And they're becoming more ... trying to become more middle-class.' (Link worker, female, Bengali)

Another respondent suggested that in such instances the influence of the family can sometimes affect their use of services:

'I think when you go down to the issue of parent-craft and who comes to the classes, many ladies, the second-generation ladies, will say "I need to go home and I need to ask if I can come to them". There is still very much that the family is in charge of what they do. I think as well it tends to be if they live with their families then it's even more of a "we have to ask permission". If they live with just their husband, on their own, then they're very much more independent and making their own decisions.' (Midwife, female, ethnicity not known)

Many respondents appreciated the ability of UK-born women to articulate their needs as it enhanced their care options. Two midwives, in a unit with significant proportion of African mothers, commented that less expressive women may get 'lower standards of care or less choice':

'Women with perhaps lower expectations or who are less articulate and less able to make demands are disadvantaged because they don't know how to ask.' (Midwife, female, white British)

Some professionals also felt that migrant women were more accommodative and 'straightforward' in their demands whereas they needed to do a 'lot more to appease a white mother' and that UK-born ethnic minority mothers 'are catching up fast with that sort of thing'. There were also impressions that women who were expressive could be viewed as 'too demanding' in situations 'where they're stretched and they're looking after more than one woman'. Two midwives expressed their worries about the higher chances of litigation they faced in the event of adverse outcomes for UK-born women compared to migrant women.

It was also felt that UK-born ethnic minority mothers would be more likely to want to consult with someone else other than the professionals whereas migrant women would be more likely to let the health professionals 'take the lead' in their care.

\section{Stereotypes and typifications}

Many professionals felt that the use of stereotypes was less common than it had been:

'This is such a multicultural area that ... and because many of us have grown up in British society we tend not to stereotype. I mean ... sometimes ... you do ... but then I think it's the same with every group. You know the Asians will talk about Asians just come from India, black people talk about the Yardies [a general term applied to Afro-Caribbean gangsters operating in the UK], those who've just come over from Jamaica, but on the whole I don't think people stereotype as much as they used to, no.' (Health visitor, female, black Caribbean)

There were, however, preconceived ideas about how various ethnic groups fare in maternity issues:

\begin{abstract}
'They [Indians] fare better than the Pakistanis that come from a poorer background. But they've both got the extended family. The Irish UK second generation, not all but there's a higher incidence of smoking and health-related problems there. The Afro-Caribbeans probably ... I'm doing probably a little bit of stereotyping here but what springs to mind is being a single mother with a few babies, maybe even from different partners. I've come across that. And again that can go back down to education, family support and their financial situation. Springing to mind now quickly, UK-born Afro-Caribbean would probably be, there probably wouldn't be a permanent partner. Multiple partners. It's quite common.' (Midwife, female, Irish)
\end{abstract}

Some professionals also perceived UK-born Caribbean women to be aggressive during clinical interactions:

'No, some of them would be second generation, certainly the West Indian girls are very in your face, very cheeky, very loud and aggressive, can be aggressive, verbally. Thank God not physically yet, but yeah ... they can be quite aggressive...' (Midwife, female, white British)

The expression and tolerance of pain in labour and the use of analgesics was commented upon. The impression was that ethnic minority women, especially South Asians, express their pain and tend to have a low pain threshold:

'Indian women, without a doubt, have a lower pain threshold, without a doubt.' (Midwife, female, white British) 
'I tell this joke as saying that if I had one Somali woman in labour in City Road you'll hear her at Main Street Station. If you have a Pakistani woman you'll hear her at Five Ways, and if you have an English woman you might hear it a little, you know. So I think that's another cultural difference...' (General practitioner, male, Indian)

There was also an impression that mothers with an African background view pregnancy and childbirth as natural events and would not normally use pain relief.

The other expectation was a preference for hospital birth among ethnic minority women. The assumption was that it is the 'empowered, articulate, educated women that go for home deliveries' who are more 'likely to be more like the white indigenous population'. If women from ethnic minority backgrounds expressed preference for a home birth, respondents tended to treat this as a surprise with 'raised eyebrows'. The demands of such women were understood to be 'more in line with their white counterparts'. Views that socioeconomically disadvantaged women prefer medicalized care and analgesics 'seem to be more to do with class' also came up repeatedly:

'I think if they're lower socioeconomic groups they probably actually want to have an epidural and want to have very medicalized care and still see the doctor as the important person.' (Midwife, female, white British)

\section{Discussion}

Few studies have focused on professionals' perspectives of UK-born ethnic minority women's maternity experiences. This makes it difficult to compare the findings with previous studies. Our analysis of women's views showed consensus between their views and those of professionals on some of the issues raised ${ }^{20}$ but it was unable to explore how professionals' attitudes and perceptions influenced patient encounters or the care provided. While some of the professionals we interviewed came from ethnic minority groups themselves, the study was too small to explore how this might have influenced their perspectives.

\section{Perceptions of 'hybrid ethnicity' with language competence}

The potential importance of ethnicity as a form of identity has been discussed and investigated elsewhere. ${ }^{21,22}$ UK-born women from ethnic minorities could be influenced by multiple cultures that produces hybrid identities. ${ }^{23}$ This may be reflected in their language, accent or dress which health care professionals in our study used to distinguish UK-born mothers from migrant mothers. The meaning of these symbols is then negotiated to constitute a social identity with specific behavioural expectations creating new social worlds in service delivery. Such behavioural expectations could also arise from professionals' views of cultural differences rather than norms that are valid to the women. Assumptions, such as a transition in habits corresponds with a transition in needs or values, fail to recognize the potential duality of cultures. For example, 'Westernized dress' or a British accent could be mistakenly interpreted as corresponding to the lack of retention of traditional practices. ${ }^{11}$

Studies of white British women's experiences have identified effective communication as a fundamental prerequisite for quality in maternity care. ${ }^{16,24,25}$ Language difficulties among migrant women were repeatedly cited even though almost all the maternity units have established language support or advocacy services. Although some of the professionals mentioned using such services with migrant women, it was unclear the extent to which these services were being used. The current study was not primarily intended to explore barriers that may be faced by migrant women but our findings and those of others ${ }^{14}$ suggest that this is an area which warrants continued attention.

\section{Potential impact of behavioural expectations on service delivery}

Our findings indicated behavioural expectations of professionals towards UK-born ethnic minority women and some less obvious stereotypes. While assertiveness, expressiveness and decision-making autonomy were seen to be more positive in affecting service delivery, such expectations coupled with low staff morale could potentially mediate service delivery.

Stereotyping of ethnic minority women by midwives is a frequent theme in research. ${ }^{8,10-12}$ Such conscious and unconscious beliefs by professionals can influence clinical decision-making and contribute to ethnic disparities. For instance, if Indian women are perceived to have a low pain threshold, professionals may encourage them to use analgesia. On the other hand, if African women are perceived to prefer an interventionfree, natural labour, this might lead professionals to avoid discussing the options for pain relief with them. If women are typified based on their ethnicity and not as individuals they may be disadvantaged. ${ }^{8}$

While categorization and generalization have been identified as adaptive strategies to make the social world more manageable, such assumptions fail to consider individual differences within groups. It could also hinder professionals from giving required information to make an informed choice. Although subtle and less obvious, such attitudes could reflect elements of institutionalized racism and point to the need for intervention strategies.

\section{Education, class or ethnicity?}

Respondents perceived differences in the behaviour of women, especially the Irish, by social class and education, with educated middle class women perceived as compliant and preferring an intervention-free labour, regardless of their ethnicity. This perception is consistent with findings from studies of working class women's 
expectations and experiences of childbirth in the 1980s in the $\mathrm{UK}^{26}$ and US. ${ }^{27}$ These found that natural childbirth meant little to these mothers and that they preferred to use analgesics so as to have a labour that was free of pain. In contrast, large prospective studies among women in south-east England showed that aspirations for a drug-free labour were unrelated to education or social class. ${ }^{28,29}$ The professionals in our study linked women's educational backgrounds to their knowledge of maternity issues. Access to knowledge is central to women's ability to make choices and this may be restricted for disadvantaged women. ${ }^{30}$

\section{Conclusion}

Our findings cannot be considered to be representative of all professionals' views of UK-born ethnic minority mothers. Although the initial study design included triangulation with both focus group discussions and in-depth interviews, focus groups were dropped due to logistic issues. This might have affected the reliability of the findings, but in-depth interviews were found to be more suitable for exploring the complex subjective dimensions of perceptions.

Overall, professionals felt it easier to provide services to UK-born women than to immigrant women. They did not experience cultural barriers with UK-born ethnic minority women. This may be because they were of varied ethnic background themselves but this was not explored in the study. Despite this, specific behavioural expectations and stereotypical views were evident and these have the potential to affect clinical practice. Since many of these beliefs are unconsciously activated, it is also unclear whether cultural competence programmes alone will have any impact. Improving interpersonal and communication skills, active listening skills and self-awareness among professionals could promote greater women-focused care in maternity services.

\section{Acknowledgements}

The project was initially funded by the Community Fund, now known as the Big Lottery, through a grant to the Maternity Alliance. After Maternity Alliance went into insolvency, the funding was transferred to Women's Health and Family Services. The authors would like to thank the former staff of the Maternity Alliance especially Christine Gowdridge, Ruba Sivagnanum, Ros Bragg and Mary Makoni; Shamoly Ahmed and Carol Dossett from City University and the staff at Women's Health and Family Services, especially Joyce Grandison and Pam Shickler for their support. We would also like to thank all our participants for giving their time and energy to this project.

\section{References}

1 Department of Health. Race Equality Scheme 2005-2008. London: Department of Health, 2005. See http://www.dh. gov.uk/en/Publicationsandstatistics/Publications

PublicationsPolicyAndGuidance/DH_4112158 (last checked 26 October 2007)

2 Department of Health. Maternity matters: choice, access and continuity of care in a safe service. London: Department of Health, 2007
3 Rudat K, Roberts C, Chowdhury R. Maternity Services: A Comparative Survey of Afro-Caribbean, Asian and White Women. London: MORI Health Research, 1996

4 van Ryn M, Burke J. The effect of patient race and socio-economic status on physicians' perceptions of patients. Soc Sci Med 2000;50:813-28

5 van Ryn M. Research on the provider contribution to race/ ethnicity disparities in medical care. Med Care 2002;40 (Suppl. 1):I140-I151

6 van Ryn M, Fu SS. Paved with good intentions: do public health and human service providers contribute to racial/ ethnic disparities in health? Am J Public Health 2003;93: 248-55

7 Shelton JD. The provider perspective: Human after all. Int Fam Plann Perspect 2001;27:152-3, 161

8 Bowler I. 'They're not the same as us': midwives' stereotypes of South Asian descent maternity patients. Sociol Health Illn 1993;15:157-78

9 Bertakis KD, Callahan EJ, Helms EJ, Azari R, Robbins JA. The effect of patient health status on physician practice style. Fam Med 1993;25:530

10 Barj K. Providing midwifery care in a multicultural society. Midwifery 1995;3:271-6

11 Ellis N. Birth Experiences of South Asian Muslim Women: marginalised choice within the maternity services. In: Kirkham M, ed. Informed Choice in Maternity Care. London: Palgrave Macmillan, 2000

12 Woollett A, Dosanjh-Matwala N, Hadlow J. Reproductive decision making: Asian women's ideas about family size, and the gender and spacing of children. JRIP 1991;9:237-52

13 Bowes AM, Domokos TM. Your dignity is hung up at the door: Pakistani and white women's experiences of childbirth. In: Earle S, Letherby G, eds. Gender Identity and Reproduction: Social Perspectives. Basingstoke: Palgrave Macmillan, 2003

14 Bulman KH, McCourt C. Somali refugee women's experiences of maternity care in west London: a case study. Crit Publ Health 2002;12:365-80

15 Proctor S. What determines quality in maternity care? Comparing the perceptions of childbearing women and midwives. Birth 1998;25:85-93

16 Schott J, Henley A. Antenatal care in a multiracial society. Modern Midwife 1996;6:30-1

17 Lincoln YS, Guba EG. Naturalistic Inquiry. Beverly Hills, CA: Sage, 1985

18 QSR International. QSR Nvivo2 for Windows 2000, XP and ME. Doncaster, Victoria, Australia: QSR International, 2000

19 Glaser BG, Strauss AL. The Discovery of Grounded Theory: Strategies for Qualitative Research. New York, NY: Aldine De Gruyter, 1967

20 Puthussery S, Twamley K, Macfarlane A, Harding S. Maternity care experiences of ethnic minority women born in the United Kingdom: Perceptions of mothers and health care providers [Abstract]. Eur J Public Health 2006;16 (Suppl. 1):176

21 Karlsen S, Nazroo JY. Agency and structure: the impact of ethnic identity and racism in the health of ethnic minority people. Sociol Health Illn 2002;24:1-20

22 Nazroo JY, Karlsen S. Patterns of identity among ethnic minority people: diversity and commonality. ERS 2003;26: 902-30

23 Hall S. 'The question of cultural identity' In: Hall S, Held D, McGrew T, eds. Modernity and its Futures. Cambridge: Polity Press, 2002

24 Department of Health. Changing child birth (part 2): Survey of good communication practice in maternity services. London: HMSO, 1993

25 Rowe RE, Garcia J, Macfarlane AJ, Davidson LL. Does poor communication contribute to stillbirths and infant deaths? A review. J Public Health Med 2001;23:23-34

26 McIntosh J. Models of child birth and social class: A study of 80 working class primagravidae. In: Robinson S, Thomson 
AM, eds. Midwives, Research and Child Birth. London: Chapman and Hall, 1989

27 Nelson MK. Working class women, middle class women and models of child birth. Soc Probl 1983;30:284-97

28 Green JM, Coupland VA, Kitzinger JV. Expectations, experiences, and psychological outcomes of childbirth: a prospective study of 825 women. Birth 1990;17:15-24
29 Green JM. Expectations and experiences of pain in labor: findings from a large prospective study. Birth 1993;20:65-72 30 Lazarus E. What do women want? Issues of choice, control and class in American pregnancy and childbirth. In: Davis-Floyd RE, Sargent CF, eds. Childbirth and Authoritative Knowledge: Cross-cultural Perspectives. Berkeley, CA: University of California Press, 1997 